\title{
The Crystal Structures of the Orientationally Disordered, Cubic High-temperature Phases of Univalent Metal Perchlorates
}

\author{
K. O. STRØMME
}

Department of Chemistry, University of Oslo, Blindern, Oslo 3, Norway

\begin{abstract}
A model of the orientationally disordered crystal structures of the cubic, high-temperature phases of a series of isostructural univalent metal perchlorates has been proposed. The perchlorate ions are found to occupy statistically two distinct sets of orientation in a given frame of the metal ions. Each set comprises a number of crystallographically equivalent orientations separated by potential barriers. X-Ray diffraction and transition entropies are interpreted in terms of the model.
\end{abstract}

The crystalline perchlorates of sodium, ammonium, potassium, rubidium, cesium, univalent thallium, and silver transform into a cubic high temperature phase ${ }^{1}$ at higher temperatures (Table 1). Apart from sodium and (possibly) silver perchlorate, the compounds are isostructural at room temperature, the ratios of the axes of the orthorhombic unit cell being nearly the same for all compounds. ${ }^{2}$ The crystal structures of the room-temperature phases of ammonium, potassium, and sodium perchlorate have been reported. ${ }^{3-7}$ Sodium perchlorate transforms gradually into the high-temperature phase on heating. The other compounds change rather abruptly into the new phase. Decomposition of most perchlorates occurs at temperatures considerably above the transition points. ${ }^{8}$

The cubic high-temperature phases are facecentred with four formula units per unit cell (Table 1).9,10 Finbak and Hassel suggested that the anion polyhedra rotate in the high temperature phases. ${ }^{16}$ Referring in particular to sodium, ammonium and potassium perchlorate, a plausible rotation model was presented according to which the tetrahedrons rotate about the [100]-, [010]-, and [001]-directions, the chlorine atoms being situated at the origin and the metal ions in $\left(\frac{1}{2} \frac{1}{2} \frac{1}{2}\right)$ etc., as proposed previously. ${ }^{2, I_{n}}$ The model was not checked in detail against experimental data. The idea that the hightemperature phases are disordered is supported by other kinds of evidence, such as the high transition heats observed in these solids (Table 1).

In agreement with more recent views, ${ }^{17,18}$ the polyatomic anions are in this work assumed to librate in preferred orientations most of the time (Frenkel model of disorder), rather than to rotate more or less freely in the disordered phases (Pauling model). The latter case represents a strongly excited state compatible with relatively high temperatures. Only a few exam. ples of quasi-free rotation are known in the solid state according to Janik et al. ${ }^{19}$ An example is the ammonium ion in ammonium per. chlorate. ${ }^{19-22}$

\section{EXPERIMENTAL}

Commercially available sodium and potassium perchlorate were used without further purification. The other compounds were obtained from aqueous solutions prepared by adding together solutions of approximately equimolecular amounts of perchloric acid and one of the metal salts (carbonate or chloride), and evaporating subsequently the excess water. The crystals were purified by repeated crystalliza. tions from aqueous solutions and dried at about $150^{\circ} \mathrm{C}$.

The Bragg reflections of powdered samples of sodium, ammonium, potassium, and rubidium perchlorate were recorded with an automatic X-ray diffractometer, model GEXRD3, equipped with a high-temperature X-ray diffractometer furnace, Model TemPres Sx, using CuK $\alpha$ radiation. The precision of the temperature 


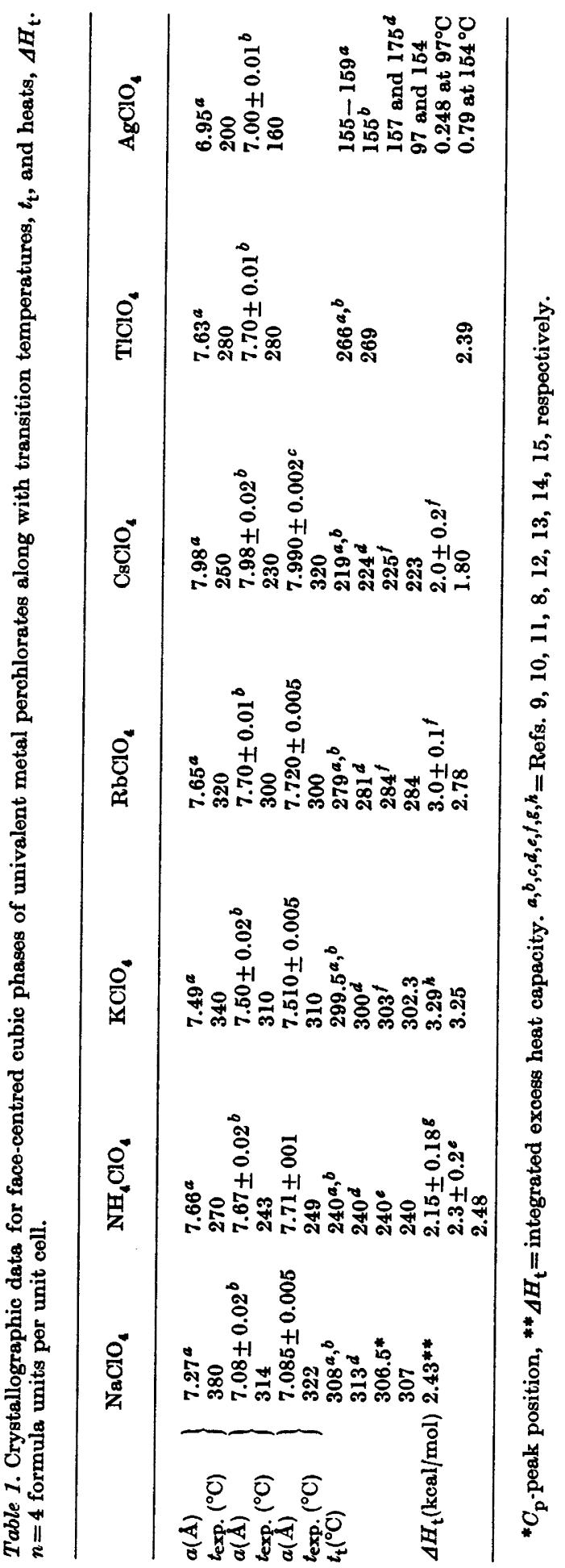

Acta Chem. Scand. A 28 (1974) No. 5 
reading is about $\pm 2{ }^{\circ} \mathrm{C}$. Ammonium perchlorate was sealed in (pyrex) capillaries subsequently mounted in the sample holder, to avoid dissociation and sublimation. The other samples were pressed gently into the sample holder to minimize orientational effects. The intensity of certain reflections changed slightly in some cases from one run to the other, possibly due to orientational effects. The intensities of the graphically recorded reflections were obtained by weighing the areas under the intensity peaks and corrected for systematic effects due to multiplicity, orientational and polarization factors in the usual way. Structure factor amplitudes are listed in Table 5.

The heat capacity of sodium perchlorate was measured in the temperature range from 26 to $409^{\circ} \mathrm{C}$, using an adiabatic calorimeter. ${ }^{23}$ The polycrystalline sample of about $50 \mathrm{~g}$ was preheated in a quartz holder to about $380^{\circ} \mathrm{C}$ before the measurements were started. Two series of measurements were made. Peak details were studied in the second run. For some unknown reason, the peak shifted slightly towards higher temperatures in the second run.

Numerical results are listed in Table 2. The precision in single temperature and heat capacity measurements ranges from 0.01 to $0.1^{\circ} \mathrm{C}$ and from 0.2 to $0.6 \%$, respectively. ${ }^{23}$ The heat capacity of the first series is plotted against temperature in Fig. 1. The transition starts very slowly between 350 and $400 \mathrm{~K}$. The rate of change of the heat capacity increases gradually with temperature till a maximum and then decreases until the heat capacity approaches a constant value. Then a very strong increase sets in, the curve passes through the maximum at

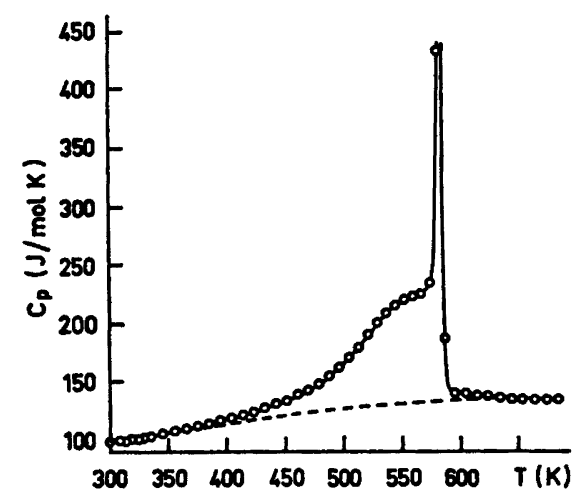

Fig. 1. Heat capacity of sodiurn perchlorate plotted against temperature.

Table 2. Heat capacity of solid sodium perchlorate from room temperature to about $410^{\circ} \mathrm{C}$. Peak maximum at about 579.6 $\mathrm{K}$ according to the second run. Asterisk denotes the first measurement (after a break), which is somewhat uncertain.

\begin{tabular}{|c|c|c|c|c|c|}
\hline \multicolumn{4}{|c|}{ First run } & \multicolumn{2}{|c|}{ Second run (peak details) } \\
\hline $\begin{array}{l}T \\
(\mathrm{~K})\end{array}$ & $\begin{array}{l}C_{\mathrm{p}} \\
(\mathrm{J} / \mathrm{K} \mathrm{mol})\end{array}$ & $\begin{array}{l}T \\
(\mathrm{~K})\end{array}$ & $\begin{array}{l}C_{\mathrm{p}} \\
(\mathrm{J} / \mathrm{K} \mathrm{mol})\end{array}$ & $\begin{array}{l}T \\
(\mathrm{~K})\end{array}$ & $\begin{array}{l}C_{\mathrm{p}} \\
(\mathrm{J} / \mathrm{K} \mathrm{mol})\end{array}$ \\
\hline 315.0 & 99.3* & 528.6 & 199.9 & 299.1 & $98.5^{*}$ \\
\hline 325.3 & 101.2 & 536.2 & 207.9 & 309.5 & 99.5 \\
\hline $\mathbf{3 3 5 . 4}$ & 103.3 & 543.7 & 214.9 & 319.7 & 100.8 \\
\hline 345.5 & 105.5 & 551.1 & 220.1 & 329.9 & 102.0 \\
\hline 355.5 & 107.2 & 558.4 & 222.7 & 576.2 & $464.3^{*}$ \\
\hline 365.4 & 109.2 & 565.7 & 225.1 & 576.9 & 450.6 \\
\hline $\mathbf{3 7 5 . 3}$ & 111.7 & 573.0 & 235.2 & 577.6 & 478.5 \\
\hline 385.0 & 113.6 & 578.9 & 433.0 & 578.4 & 464.0 \\
\hline 394.8 & 116.0 & 585.3 & $186.6 *$ & 578.9 & 791.8 \\
\hline 404.4 & 118.3 & 594.2 & 140.1 & 579.2 & 1334.4 \\
\hline 414.0 & 120.7 & 603.7 & 139.5 & 579.5 & 1623.2 \\
\hline 423.5 & 123.4 & 613.3 & 138.0 & 579.7 & 1536.1 \\
\hline 432.9 & 127.1 & 623.0 & 137.7 & 579.9 & 1215.4 \\
\hline 442.3 & 130.3 & 632.8 & 136.5 & 580.4 & 616.8 \\
\hline 451.6 & 133.1 & 642.6 & 135.5 & 581.1 & 328.5 \\
\hline 460.7 & 138.3 & 652.5 & 135.4 & & \\
\hline 469.8 & 142.0 & 662.4 & 134.7 & & \\
\hline 478.7 & 147.2 & 672.4 & 135.5 & & \\
\hline 487.4 & 154.1 & 682.5 & 134.8 & & \\
\hline 496.1 & 161.8 & & & & \\
\hline 504.5 & 170.4 & & & & \\
\hline 512.7 & 178.7 & & & & \\
\hline 520.8 & 189.7 & & & & \\
\hline
\end{tabular}

Acta Chem. Scand. A 28 (1974) No. 5 
about $580 \mathrm{~K}$ and drops off very quickly to a "normal", approximately constant heat capacity at $650 \mathrm{~K}$. This remarkable behaviour of the heat capacity indicates that the transition is a compound process, occurring in several steps. A further study of this requires more experimental data for the transition region. However, some general comments may be appropriate. The process is presumably an orientational order-disorder process. At room temperature, the $a$ and $b$-axes are very similar, the reported values being not significantly different from the cubic axis measured at about $314^{\circ} \mathrm{C}$, while the $c$-axis is considerably shorter. Inspection of the crystal structure and space group indicates that the structure may pass through a tetragonal phase before changing into the cubic structure.

The integrated excess heat capacity was determined by weighing the peak bounded by the heat capacity curve and a smooth curve drawn below the peak in Fig. 1, etc. The integrated excess heat capacity divided by the absolute temperature was determined in a similar way. These quantities, put equal to the heat and entropy of the transition, respectively, are given in Table 1 and Table 8, respectively. The actual fraction of the given figures attributable to changes in orientational order alone, is somewhat uncertain because of the arbitrariness as. sociated with drawing the basis line extending over a considerable temperature interval.

Differential scanning calorimetry curves of polycrystalline samples were run for all compounds, using a Perkin Elmer differential scan. ning calorimeter and indium as reference substance. The peak areas were determined by weighing as in the preceding case. Numerical results are listed in Table 1 . Diff. scan. curves are shown in Fig. 2. The standard deviation in the measured peak areas is of the order of $1 \%$. The diagrams of silver perchlorate contain four endotherms, of which the two small peaks are not represented in Table 1 . These endo- therms changed in repeated runs, the others not. The origin of the first three peaks is not certain. They have been suggested to originate in absorbed moisture. ${ }^{8}$

\section{SPACE GROUP}

The following space groups are compatible with the extinction rules of the $\mathrm{X}$-ray reflections: F23, $F 43 m, F 432, F m 3$, and $F m 3 m$, of which the two first ones were chosen in the original model assuming an ordered structure,${ }^{10,13}$ while the last one corresponds to the rotationally disordered structure of Finbak and Hassel. ${ }^{16}$ Only the last two space groups are centrosymmetric. Since the ordered room temperature phases are centrosymmetric, the high-temperature phases are probably centrosymmetric too. The difference between the two centrosymmetric space groups is that $F m 3 m$ possesses a mirror plane in the (100) plane etc., Fm3 not. Since there is apparently no long range order in these high-temperature phases, two positions equivalent via this mirror plane must be considered equally probable. This leaves $F m 3 m$ as the most probable space group of the statistical structure. The same space group is also found in a number of other, disordered, face-centred cubic structures. ${ }^{24-26}$

\section{MOLECULAR EQUILIBRIUM POSITIONS}

The perchlorate ions are assumed to be situated at $(000),\left( \pm \frac{1}{2}, \pm \frac{1}{2}, 0\right),\left(0, \pm \frac{1}{2}, \pm \frac{1}{2}\right)$ and $\left( \pm \frac{1}{2}, 0, \pm \frac{1}{2}\right)$ etc., with the metal ions in the

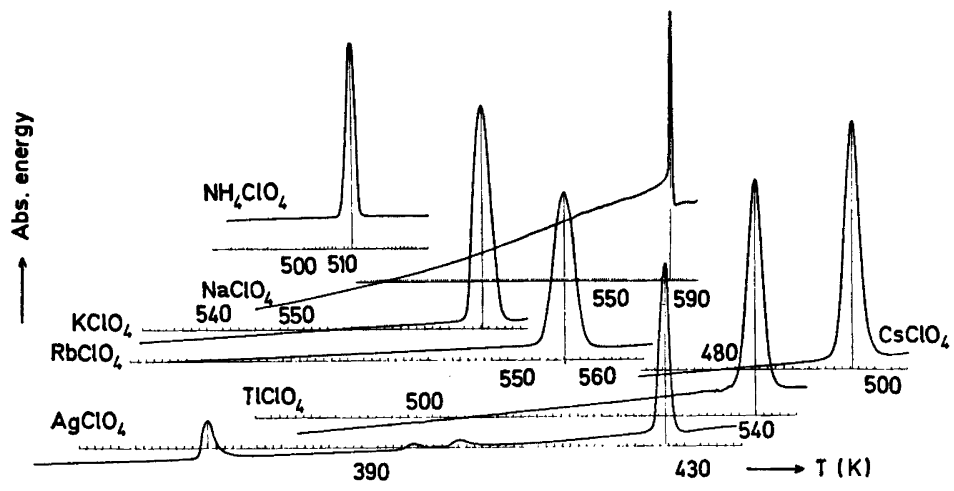

Fig. 2. Differential scanning calorimetry diagrams. Heating rate: $8^{\circ} \mathrm{C} / \mathrm{min}$.

Acta Chem. Scand. A 28 (1974) No. 5 
average positions $\left( \pm \frac{1}{2}, 0,0\right),\left(0, \pm \frac{1}{2}, 0\right),\left(0,0, \pm \frac{1}{2}\right)$ and $\left( \pm \frac{1}{2}, \pm \frac{1}{2}, \pm \frac{1}{2}\right) e t c$., in agreement with previous assumptions. ${ }^{8,10}$ The problem is to locate the statistical equilibrium orientations of the anions at these sites. The main intermolecular attraction originates in neighbouring metal-oxygen interactions, while coulombic repulsions ${ }^{27}$ should tend to maximize chlorine-metal separations. The oxygen-metal equilibrium contact distances are assumed to be relatively close to the sum of the van der Waals and ionic radii for these atoms, ${ }^{28}$ respectively, in agreement with observations in other orientationally disordered solids, ${ }^{24,28-82}$ and in ordered structures, ${ }^{3-7,38-86}$ which may, however, show a considerable variation in the metal-oxygen contact distance, as reflected in the lower crystal symmetry.

Furthermore, at least three oxygen atoms of the perchlorate ion are assumed to participate in "bond" formation with metal ions in the equilibrium state. Inspection shows that only a small orientational change is in general needed to turn a perchlorate ion, having only two $\mathrm{O}$ atoms in close contact with neighbouring metal ions, into a position where three or all four oxygens make close contact with the other species.

It seems also reasonable to expect the perchlorate ions to be situated (statistically) in special positions of the space group, given that the metal ions are in special positions. The perchlorate ion is assumed to be tetrahedrally sym. metric with a given chlorine-oxygen bond length.

The distinct molecular orientations considered as possible, statistically averaged, equilibrium positions of the anion are given in Fig. 3, including the corresponding numbers of equivalent orientations per site according to $F m 3 m$. The positions represent a great variety of orientations, when all equivalent orientations are taken into account. However, a general orientation of the anion is missing because it was difficult to select one such position not closely related to one of those already shown, or which seemed likely as an equilibrium orientation according to the rules mentioned.

The various, equivalent orientations of a given set are in principle separated by potential barriers, since reorientation from one position to another requires breaking original $\mathrm{O}-\mathrm{Me}$

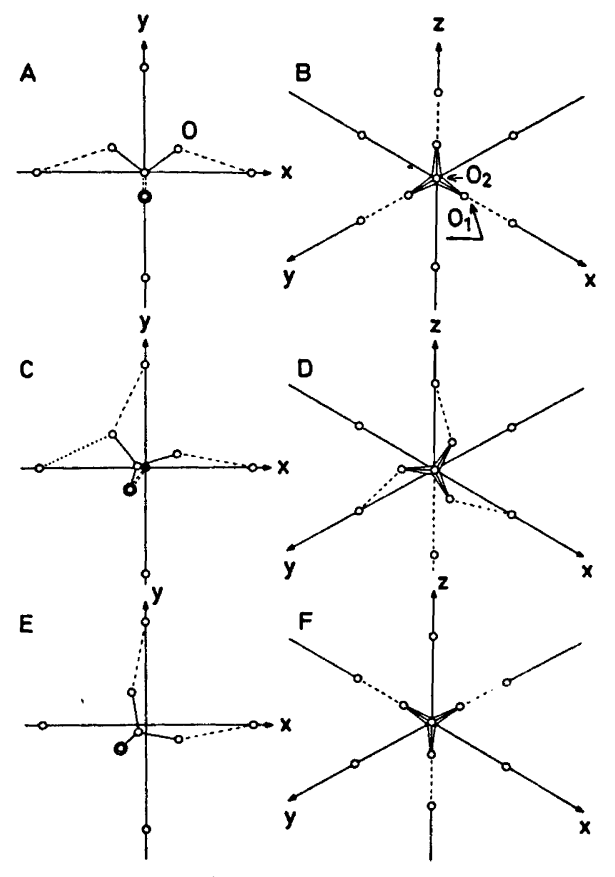

Fig. 3. Various orientations of the perchlorate ion in the face-centred cubic unit cell. Location of molecular symmetry elements and number of crystallographically equivalent orientations per molecule:

A: $\overline{4} \|[010],[101]$ and $[\overline{1} 01] ; g=6$.

B: $3 \|[111] ; g=8$.

C: $\overline{4}$ and $m$ in (001); $g=24$.

D: $3 \|[111] ; g=16$.

E: $4 \|[110] ; g=12$.

F: $3 \|[111],[\overline{1} 11],[1 \overline{1} 1]$ and $[11 \overline{1}] ; g=2$.

"bonds" and establishing new ones in the equivalent orientation.

Molecular positions $\mathrm{A}$ and $\mathrm{F}$ are locked with the chlorine atom at the origin. In the other models, the $\mathrm{O}-\mathrm{Me}$ distances may be adjusted by translation (B, E, D) and/or rotation (C), keeping the molecule in the same special position. $A$ and $B$ were found to satisfy reasonably well the requirements discussed above. $\mathrm{O}-\mathrm{Me}$ distances are listed in Table 3. The contact distances calculated in $\mathrm{A}$ are in general not much different from those assumed in $\mathrm{B}$, except perhaps for $\mathrm{NaClO}_{4}$. However, reported $\mathrm{Na}-\mathrm{O}$ contact separations show a relatively wide distribution about the average value. The corresponding distances listed for $\mathrm{CsClO}_{4}$ are con-

Acta Chem. Scand. A 28 (1974) No. 5 


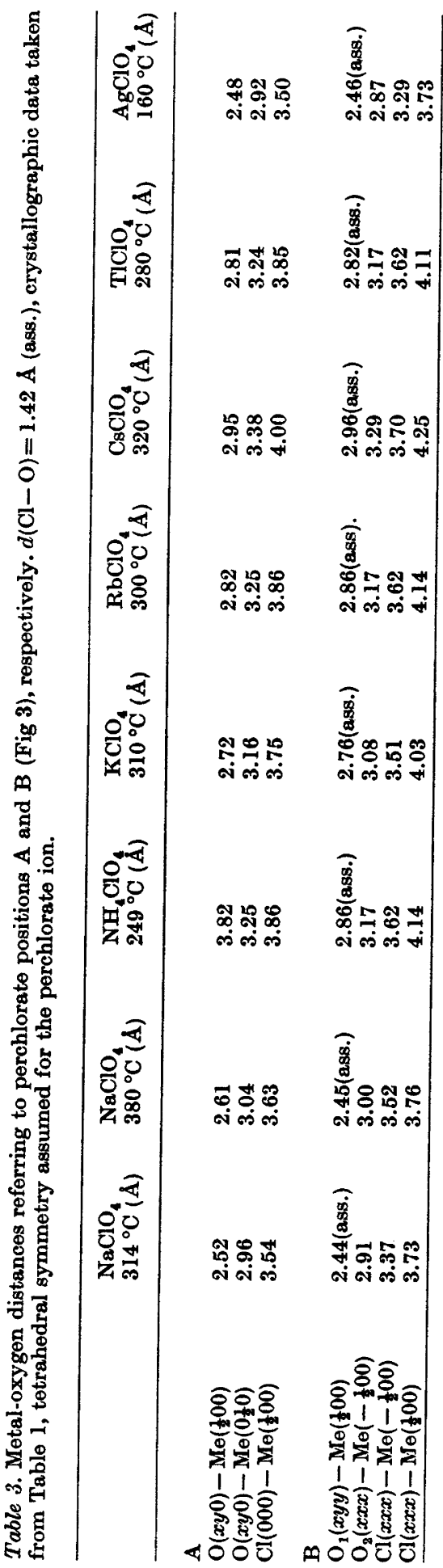

Acta Chem. Scand. A 28 (1974) No. 5 
siderably less than the sum of the reported contact radii $(3.09 \AA)$ and may possibly be too short in the equilibrium state. This would rule out $A$, in agreement with the result of the entropy analysis, which indicates that $\mathbf{A}$ or $\mathbf{B}$ is inaccessible.

C is the most asymmetric position shown in Fig. 3. Two $O$ atoms and the $\mathrm{Cl}$ atom are placed in the (001) mirror plane. The number of $\mathrm{O}-\mathrm{Me}$ contacts is generally quite reasonable, the arrangement of such contacts appears, how. ever, to be somewhat arbitrary. $C$ may be changed into $A$ by a relatively small positional shift, establishing a close $\mathrm{O} 2-\mathrm{Me}\left(-\frac{1}{2} 00\right)$ contact at the expence of the $\mathrm{O} 2-\mathrm{Me}\left(0 \frac{1}{2} 0\right)$ contact. Although $\mathrm{C}$ may not appear likely at equilibrium, it cannot presently be definitely ruled out. The subsequent analysis indicates, however, that C-population is either small or zero.

In $B$ and $D$, three $O$ atoms are in close contact with three metal ions. $D$ may be transferred into $B$ without breaking any of the $\mathrm{Me}-\mathrm{O}$ contacts. These two positions are therefore hardly separated by a potential bar. rier. The $\mathrm{O}-\mathrm{Me}$ contacts in $\mathrm{B}$ resemble the "aragonite-type" found in univalent metal nitrates. ${ }^{27-20}$

Position E, involving two $\mathrm{Me}-\mathrm{O}$ contacts only, may, for instance, be transferred into one of the $A$ equivalents by rotating an angle of $45^{\circ}$ about and translating the group along the [110]-direction, without breaking the $\mathrm{O}-\mathrm{Me}$ contacts. E represents therefore hardly a potential minimum at all.

In $\mathrm{F}$ the $\mathrm{O}-\mathrm{Cl}$ bonds lie along the four equivalent body diagonals of the unit cell. The $\mathrm{O}-\mathrm{Me}$ contacts are too long to render the position likely as an equilibrium orientation. The population of $\mathbf{F}$ would at any rate be expected to be small. The most probable equilibrium positions are thus $A$ and $B$, giving rise to a satisfactory interpretation of $X$-ray and transition entropy data for these compounds.

\section{ANALYSIS OF X-RAY DIFFRACTION DATA}

X-Ray structure factor sets were calculated for $A$ and $B$, assuming all atoms to be neutral. The form factors of Hanson et al. were used. ${ }^{32}$ Basic positional parameters are listed in Table 4. The $\mathrm{Cl}-\mathrm{O}$ bond length was assumed equal to $1.42(0.02) \AA$, which is the average value of recently reported $\mathrm{Cl}-\mathrm{O}$ distances in perchlorates $0,88,20$ (e.s.d. in parenthesis). The positions of the hydrogen atoms in ammonium perchlorate are not known. A spherical 10 distribution of these atoms centred about $\mathrm{N}$ at a distance of $1.02 \AA$ (NH bond length) was therefore assumed, corresponding to (quasi) free rotation of the ammonium group. A linear combination of the two sets of structure factors was formed. Thus, $F_{\mathrm{c}}=x_{\mathrm{A}} F_{\mathrm{A}}+x_{\mathrm{B}} F_{\mathrm{B}}$, where $F_{\mathrm{A}}$ is the calcu. lated structure factor based on model $A$ and

Table 4. Positional coordinates for atoms in perchlorate ions in orientations A and B, respectively, derived from Table 2.

A. All $\mathrm{O}$ atoms crystallographically equivalent.

$x(\mathrm{Cl})=y(\mathrm{Cl})=z(\mathrm{Cl})=z(\mathrm{O})=0$

$B$. Three $O$ atoms in each ion equivalent through operation of the three-fold symmetry axis.

$x(\mathrm{Cl})=y(\mathrm{Cl})=z(\mathrm{Cl}), y_{1}(\mathrm{O})=z_{1}(\mathrm{O})$ and $x_{2}(\mathrm{O})=y_{2}(\mathrm{O})=z_{2}(\mathrm{O})$.

Metal ions at $\left( \pm \frac{1}{2} 00\right)$ etc.

\begin{tabular}{lllllllll}
\hline $\begin{array}{l}\text { Atomic } \\
\text { position }\end{array}$ & $\begin{array}{l}\mathrm{NaClO}_{4} \\
\left(314^{\circ} \mathrm{C}\right)\end{array}$ & $\begin{array}{l}\mathrm{NaClO}_{4} \\
\left(380^{\circ} \mathrm{C}\right)\end{array}$ & $\mathrm{NH}_{4} \mathrm{ClO}$ 、 & $\mathrm{KClO}_{4}$ & $\mathrm{RbClO}$ & $\mathrm{CsClO}_{4}$ & $\mathrm{TlClO}$ & $\mathrm{AgClO}$ ، \\
\hline
\end{tabular}

\begin{tabular}{lrrrrrrrr}
\hline $\mathrm{A}$ & & & & & & & & \\
$x(\mathrm{O})$ & 0.164 & 0.159 & 0.150 & 0.154 & 0.150 & 0.145 & 0.151 & 0.166 \\
$y(\mathrm{O})$ & 0.116 & 0.113 & 0.106 & 0.109 & 0.106 & 0.103 & 0.106 & 0.117 \\
$\mathrm{~B}$ & & & & & & & & \\
$x(\mathrm{Cl})$ & -0.026 & -0.017 & -0.034 & -0.035 & -0.034 & -0.030 & -0.031 & -0.032 \\
$x_{1}(\mathrm{O})$ & 0.167 & 0.171 & 0.143 & 0.147 & 0.143 & 0.141 & 0.146 & 0.163 \\
$y_{1}(\mathrm{O})$ & -0.064 & -0.054 & -0.069 & -0.071 & -0.069 & -0.065 & -0.067 & -0.071 \\
$x_{2}(\mathrm{O})$ & -0.141 & -0.129 & -0.140 & -0.144 & -0.140 & -0.133 & -0.138 & -0.149 \\
\hline
\end{tabular}

Acta Chem. Scand. A 28 (1974) No. 5 


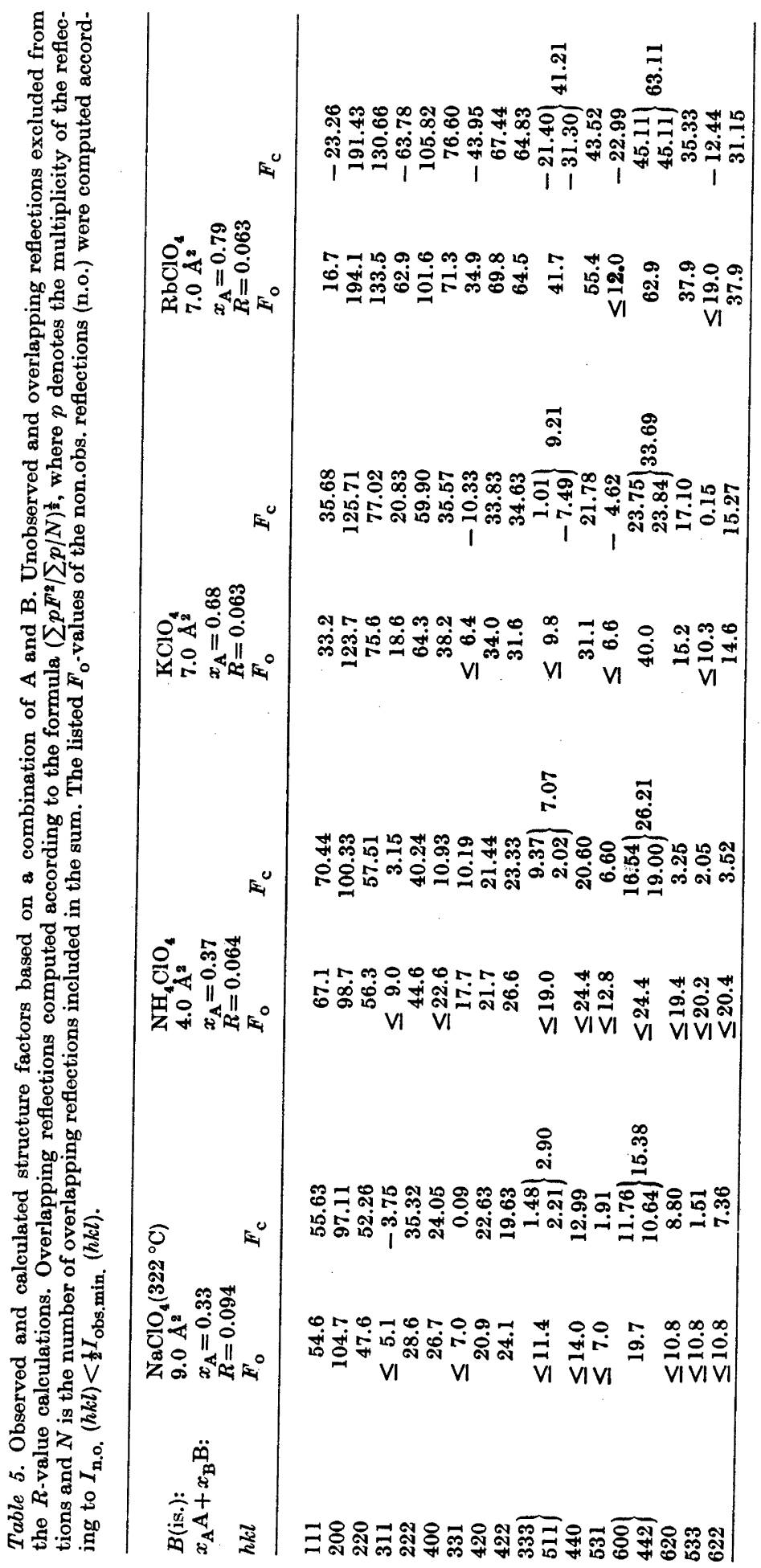

Acta Chem. Scand. A 28 (1974) No. 5 
$x_{\mathrm{A}}=1-x_{\mathrm{B}}$ is the fraction of anions occupying A-type positions etc. The linear coefficient, $x_{\mathrm{A}}$, was refined by least squares methods, using an invariant temperature factor. The weight factor, $w$, assigned to each reflection, is given as $w=$ $1 /\left[2 F_{\mathrm{o}}(\min )+F_{\mathrm{o}}+2 F_{\mathrm{o}}{ }^{2} / F_{\mathrm{o}}(\min )\right]$. The $B$-value was varied in a series of refinements. Both $R$ and $x_{\mathrm{A}}$ changed in general considerably with $B$. Observed and calculated structure factors etc., corresponding to the best agreement obtained between observed and calculated structure factors, are listed in Table 5. Systematic effects due to neglect of anisotropy in the refinement process along with the low rate of change of the $\sum w(\Delta F)^{2}$-function about the minimum value etc., render the linear coefficient values somewhat uncertain. The weighted $R$-values, $R_{\mathrm{w}}$, are from 6 (for $\mathrm{NaClO}_{4}$ ) to $33 \%$ (for $\mathrm{NH}_{4} \mathrm{ClO}_{4}$ ) less than the corresponding $R_{\mathrm{w}}$-values derived from the single structure giving rise to the best fit between observed and calculated structure factors. The corresponding agreement obtained for the non-observed and overlapping reflections on the basis of the structural combinations is considerably better than those based on the single structures in all cases studied. Finally, the present agreement factors are mostly much less than those obtained on the basis of the free rotation model.

In view of the uncertainty in the $\mathrm{Cl}-\mathrm{O}$ bond length and the translational position of the anion along the [111]-direction in case $B$, together with the approximation involved in using a common, isotropic temperature factor for all atoms etc., the agreement between observed and calculated structure factors listed in Table 5 is considered to be satisfactory. Significant improvement of the translational position of $B$ in the [111]-direction by least squares techniques appears to be unlikely in view of the present limitations. As to be expected, the $B$-values are relatively high. This is attributable to relatively large vibrational amplitudes and to the circumstance that the instantaneous equilibrium positions are distributed statistically about the mean values.

\section{INTERPRETATION OF TRANSITION ENTROPY DATA}

The number of equivalent orientations of type $A$ and $B$ is 6 and 8 per anion, respectively, ac- cording to space group $F m 3 m$. Inspection shows that many configurations implied statistically involve intermolecular $\mathrm{O}-\mathrm{O}$ separations less than the smallest separation attainable, here taken to be twice the van der Waals radius of oxygen, $2.80 \AA$. Such configurations are therefore sterically blocked and thus thermodynamically inaccessible.

Assigning a common weight factor to all accessible configurations, the configurational entropy, $S_{\mathrm{c}}$, for such a system may be expressed as ${ }^{20,31} \quad S_{\mathrm{c}}=\mathbf{k} \ln \left[W_{\mathrm{o}}(1-P)\right]$, where $\mathbf{k}=\mathrm{Boltz}$ mann constant and $P W_{0}$ is the number of sterically blocked configurations among the $W_{\mathrm{o}}$ ones implied statistically. The generally very complicated function $P$ has previously been approximated as $(1-s)^{n}$, corresponding to breaking the total system down to $n$ identical micro-systems, each of which comprising only a few lattice sites (molecules). Here each microsystem is defined as a central lattice site surrounded by $z$ neighbour sites, which comprise blocked orientations relative to one or several orientations at the central site. Since each of the $z$ neighbour sites also is surrounded by $z$ such sites, each microsystem contains effectively two lattice sites in the present case, so that $n=N / 2$, where $N$ is the total number of lattice sites associated with orientationally disordered molecules. The appropriate expressions for $w$ and $s$ are given elsewhere. ${ }^{31}$

Distances less than $2.80 \AA$ between the Oatoms denoted by their chemical symbols in $\mathrm{A}$ and $\mathrm{B}$, Fig. 3, and $\mathrm{O}$-atoms in A- and B-type positions at neighbouring lattice sites, are listed in Table 6. The O-positions situated less than $2.80 \AA$ from the other $\mathrm{O}$-atoms in $\mathrm{A}$ and $\mathrm{B}$, Fig. 3, are obtained by symmetry. The anion orientations comprising these O-positions may be identified by transforming position $A$ or $B$ to the orientation and site in question.

The number of distinct orientations of either kind situated less than $2.80 \AA$ from either $A$ or $B$ in Fig. 3 are given in Table 7, together with the associated sites. Using the results of Table 7 along with $g$-values quoted previously and the occupation numbers obtained in the preceding analysis, approximate values of the configurational entropy may now be derived in the actual cases. For thallium and silver perchlorate the occupation numbers were somewhat arbitrarily put equal to $x_{\mathrm{A}}=x_{\mathrm{B}}=0.5$, while $x_{\mathrm{A}}=0$ or 1.0

Acta Chem. Scand. A 28 (1974) No. 5 
Table 6. Intermolecular distances ( $\AA$ ) less than $2.80 \AA$ between the oxygen positions $(x y 0),\left(x_{1} y_{1} y_{1}\right)$ or $\left(x_{2} x_{2} x_{2}\right)$ given in Table 4, respectively, and equivalent oxygen positions at neighbouring sites, $\mathrm{L}$, where $(x y 0)$ belongs to the perchlorate ion orientation $A$ and the latter two to $B$ (Fig. 3) at the origin S. O-O-separations slightly less than $2.80 \AA$ are marked with an asterisk.

\begin{tabular}{|c|c|c|c|c|c|c|}
\hline $\mathbf{L}$ & $\begin{array}{l}\mathrm{NaClO}_{\&} \mathrm{NaClO}_{4} \\
\left(380^{\circ} \mathrm{C}\right)\left(314^{\circ} \mathrm{C}\right)\end{array}$ & $\begin{array}{l}\mathrm{NH} / \mathrm{ClO} \\
\left(243^{\circ} \mathrm{C}\right)\end{array}$ & $\begin{array}{l}\mathrm{KClO}_{4} \\
\left(310^{\circ} \mathrm{C}\right)\end{array}$ & $\begin{array}{l}\mathrm{RbClO}_{4} \\
\left(300^{\circ} \mathrm{C}\right)\end{array}$ & $\begin{array}{l}\mathrm{CsClO}_{4} \\
\left(320^{\circ} \mathrm{C}\right)\end{array}$ & $\begin{array}{ll}\mathrm{TIClO}_{\mathrm{f}} & \mathrm{AgClO} \\
\left(280^{\circ} \mathrm{C}\right) & \left(160^{\circ} \mathrm{C}\right)\end{array}$ \\
\hline
\end{tabular}

\begin{tabular}{|c|c|c|c|c|c|c|c|c|}
\hline $\begin{array}{l}\text { A } \quad \text { A-type } \\
O(x y 0)-O\left(\left(\frac{1}{2}-x, \frac{1}{2}-y, 0\right)\right. \\
O(x y 0)-O\left(\frac{1}{2}-y, \frac{1}{2}-x, 0\right)\end{array}$ & $\begin{array}{l}2.39 \\
2.34\end{array}$ & $\begin{array}{l}2.26 \\
2.21\end{array}$ & $\begin{array}{l}2.70 \\
2.66\end{array}$ & $\begin{array}{l}2.56 \\
2.51\end{array}$ & $\begin{array}{l}2.70 \\
2.66\end{array}$ & & $\begin{array}{l}2.69 \\
2.65\end{array}$ & $\begin{array}{l}2.20 \\
2.15\end{array}$ \\
\hline $\begin{array}{l}\mathrm{A} \\
\left.\mathrm{O}(x y 0)-\mathrm{B}(\mathrm{t}) \mathrm{t}+y_{1}, \frac{1}{2}-x_{1}, y_{1}\right) \\
\mathrm{O}(x y 0)-\mathrm{O}\left(\frac{1}{2}+y_{1}, \frac{1}{2}-x_{1}, \bar{y}_{1}\right) \\
\mathrm{O}(x y 0)-\mathrm{O}\left(\frac{1}{2}-x_{1}, \frac{1}{2}+y_{1}, y_{1}\right) \\
\mathrm{O}(x y 0)-\mathrm{O}\left(\frac{1}{2}-x_{1}, \frac{1}{2}+y_{1}, \bar{y}_{1}\right) \\
\mathrm{O}(x y 0)-\mathrm{O}\left(\frac{1}{2}+x_{2}, \frac{1}{2}+x_{2}, x_{2}\right) \\
\mathrm{O}(x y 0)-\mathrm{O}\left(\frac{1}{2}+x_{2}, \frac{1}{2}+x_{2}, \bar{x}_{2}\right) \\
\mathrm{O}(x y 0)-\mathrm{O}\left(\frac{1}{2}+x_{2}, \bar{x}_{2}, \frac{1}{2}+x_{2}\right) \\
\mathrm{O}(x y 0)-\mathrm{O}\left(\frac{1}{2}+x_{2}, \bar{x}_{2},-\frac{1}{2}-x_{2}\right)\end{array}$ & $\begin{array}{l}2.64 \\
2.64 \\
2.74^{*} \\
2.74^{*} \\
2.60 \\
2.60\end{array}$ & $\begin{array}{l}2.50 \\
2.50 \\
2.60 \\
2.60 \\
2.42 \\
2.42\end{array}$ & $\begin{array}{l}2.76^{*} \\
2.76^{*}\end{array}$ & $\begin{array}{l}2.63 \\
2.63\end{array}$ & $\begin{array}{l}2.76^{*} \\
2.76^{*}\end{array}$ & & $\begin{array}{l}2.77^{*} \\
2.77^{*}\end{array}$ & $\begin{array}{l}2.45 \\
2.45 \\
2.54 \\
2.54 \\
2.34 \\
2.39 \\
2.79 * \\
2.79 *\end{array}$ \\
\hline $\begin{array}{l}\mathrm{B} \quad \text { B-type } \\
\mathrm{O}\left(x_{1} y_{1} y_{1}\right)-\mathrm{O}\left(\frac{1}{2}+y_{1},-\frac{1}{2}+x_{1}, y_{1}\right) \\
\mathrm{O}\left(x_{1} y_{1} y_{1}\right)-\mathrm{O}\left(\frac{1}{2}+y_{1}, y_{1},-\frac{1}{2}+x_{1}\right) \\
\mathrm{O}\left(x_{1} y_{1} y_{1}\right)-\mathrm{O}\left(\frac{1}{2}-x_{1}, y_{1},-\frac{1}{2}-y_{1}\right. \\
\mathrm{O}\left(x_{1} y_{1} y_{1}\right)-\mathrm{O}\left(\frac{1}{2}-x_{1},-\frac{1}{2}-y_{1}, y_{1}\right) \\
\mathrm{O}\left(x_{1} y_{1} y_{1}\right)-\mathrm{O}\left(\frac{1}{2}+x_{2}, x_{2},-\frac{1}{2}-x_{2}\right) \\
\mathrm{O}\left(x_{1} y_{1} y_{1}\right)-\mathrm{O}\left(\frac{1}{2}+x_{2},-\frac{1}{2}-x_{2}, x_{2}\right) \\
\mathrm{O}\left(x_{1} y_{1} y_{1}\right)-\mathrm{O}\left(\bar{x}_{2},-\frac{1}{2}-x_{2},-\frac{1}{2}-x_{2}\right) \\
\mathrm{O}\left(x_{2} x_{2} x_{2}\right)-\mathrm{O}\left(x_{2},-\frac{1}{2}-x_{2},-\frac{1}{2}-x_{2}\right) \\
\mathrm{O}\left(x_{2} x_{2} x_{2}\right)-\mathrm{O}\left(-\frac{1}{2}-x_{2}, x_{2},-\frac{1}{2}-x_{2}\right) \\
\mathrm{O}\left(x_{2} x_{2} x_{2}\right)-\mathrm{O}\left(-\frac{1}{2}-x_{2},-\frac{1}{2}-x_{2}, x_{2}\right)\end{array}$ & $\begin{array}{l} \\
2.77^{*} \\
2.77^{*} \\
2.48 \\
2.48 \\
2.48\end{array}$ & $\begin{array}{l}2.54 \\
2.54 \\
\\
2.17 \\
2.17 \\
2.17\end{array}$ & $\begin{array}{l}2.40 \\
2.40 \\
2.40\end{array}$ & $\begin{array}{l}2.25 \\
2.25 \\
2.25\end{array}$ & $\begin{array}{l}2.40 \\
2.40 \\
2.40\end{array}$ & $\begin{array}{l}2.64 \\
2.64 \\
2.64\end{array}$ & $\begin{array}{l}2.44 \\
2.44 \\
2.44\end{array}$ & $\begin{array}{l}2.63 \\
2.63 \\
2.79^{*} \\
2.79^{*} \\
2.42 \\
2.42 \\
2.78^{*} \\
2.00 \\
2.00 \\
\mathbf{2 . 0 0}\end{array}$ \\
\hline
\end{tabular}

has to be chosen for cesium perchlorate if the computed configurational entropy shall not exceed the experimental value. $x_{\mathrm{A}}=0$ was chosen for two reasons. The $\mathrm{O}-\mathrm{Cs}$ contact distance obtained in the A-case is considerably shorter than the sum of the quoted contact radii and is thus possibly inaccessible. In case $B$, the O-Cs distances may be somewhat adjusted by translation of the perchlorate ion, so that this position is likely to be occupied statistically in any case.

Experimental entropy data associated with the solid phase changes are listed in Table 8 , along with calculated configurational entropies for the cubic phases. For silver perchlorate, two transition entropies are listed, corresponding to the two main peaks shown in Fig. 2 for this compound. While the origin of the first peak is not known with certainty, ${ }^{8}$ the second is assumed to originate in orientational changes of the perchlorate ions, as are those of the other compounds. Except for silver perchlorate, the transition entropies are rather high, indicat. ing that the entropy changes are dominated by configurational contributions.

The instantaneous equilibrium orientations of the anions deviate probably in general somewhat from the mean positions because of lattice interactions. As a consequence, configurations involving $\mathrm{O}-\mathrm{O}$ separations which are statistically slightly less than the smallest $O-O$ separation attainable, may actually become accessible through molecular displacements from the mean positions. This is one of the factors complicating in principle the evaluation of the configurational entropy of a given system.

Several configurational entropy values are listed for each compound in Table 8 in most cases. The unmarked $S_{\mathrm{c}}$-values are based on the assumption that configurations involving $\mathrm{O}$ - $\mathrm{O}$ separations which are statistically slightly less than $2.80 \AA$, are inaccessible, while those denoted by an asterisk are based on the assump. tion that these $\mathrm{O}-\mathrm{O}$ separations correspond to 
Table 7. The number of distinct, assumed sterically blocked orientations of perchlorate ions at neighbour sites, $L$, relative to a central perchlorate ion, $S$, in positions $A$ and $B$ (Fig. 3), respectively. The result is based on Table 6, using tetrahedral symmetry for the anion and space group $F m 3 m$, etc. Binary orientations involving $\mathrm{O}-\mathrm{O}$ separations slightly less than $2.80 \AA$, are represented in the numbers denoted by an asterisk only.

S-L $\quad$ L lattice sites

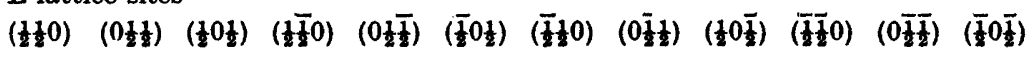

\begin{tabular}{|c|c|c|c|c|c|c|c|c|c|c|c|c|}
\hline A-A-type & $\left\{\begin{array}{l}2 \\
2 \\
2 \\
2 \\
2 \\
2 \\
2\end{array}\right.$ & & & & & $\begin{array}{l}2 \\
2 \\
2 \\
2 \\
2 \\
2 \\
2\end{array}$ & $\begin{array}{l}2 \\
2 \\
2 \\
2 \\
2 \\
2 \\
2 \\
2\end{array}$ & & & $\begin{array}{l}2 \\
2 \\
2 \\
2 \\
2 \\
2\end{array}$ & & $\begin{array}{l}\mathrm{NaClO}_{4}\left(380^{\circ} \mathrm{C}\right) \\
\mathrm{NaClO}_{4}\left(314^{\circ} \mathrm{C}\right) \\
\mathrm{NH}_{4} \mathrm{ClO}_{4} \\
\mathrm{KClO}_{4} \\
\mathrm{RbClO}_{4} \\
\mathrm{CsClO}_{4} \\
\mathrm{TlClO}_{4} \\
\mathrm{AgClO}_{4}\end{array}$ \\
\hline A-B-type & $\left\{\begin{array}{l}4,6 * \\
6 \\
2^{*} \\
2 \\
2^{*} \\
2^{*} \\
6\end{array}\right.$ & $2^{*}$ & & $2^{*}$ & & $\begin{array}{l}4,6^{*} \\
6 \\
2^{*} \\
2 \\
2^{*} \\
2^{*} \\
6\end{array}$ & $\begin{array}{l}4,6^{*} \\
6 \\
2^{*} \\
2 \\
2^{*} \\
\\
2^{*} \\
6\end{array}$ & $2^{*}$ & & $\begin{array}{l}4,6^{*} \\
6 \\
2^{*} \\
2 \\
2^{*} \\
2^{*} \\
6\end{array}$ & $2^{*}$ & $\begin{array}{l}\mathrm{NaClO}_{4} \\
\mathrm{NaClO}_{4} \\
\mathrm{NH}_{4} \mathrm{ClO} \\
\mathrm{KClO}_{4} \\
\mathrm{RbClO}_{4} \\
\text { CsClO } \\
\text { TlClO } \\
\mathrm{AgClO}_{4}\end{array}$ \\
\hline B-A-type & f & & $\begin{array}{l}1,2^{*} \\
2\end{array}$ & $\begin{array}{l}1,2^{*} \\
2\end{array}$ & $2^{1,2^{*}}$ & $\begin{array}{l}1,2^{*} \\
2\end{array}$ & $\begin{array}{l}1,2^{*} \\
2\end{array}$ & $\begin{array}{l}1,2^{*} \\
2\end{array}$ & $\begin{array}{l}2 \\
2 \\
2^{*} \\
2 \\
2^{*} \\
2^{*} \\
2,4^{*}\end{array}$ & $\begin{array}{l}2 \\
2 \\
2^{*} \\
2 \\
2^{*}\end{array}$ & $\begin{array}{l}2 \\
2 \\
2^{*} \\
2 \\
2^{*} \\
2^{*} \\
2,4^{*}\end{array}$ & $\begin{array}{l}\mathrm{NaClO}_{4} \\
\mathrm{NaClO}_{4} \\
\mathrm{NH}_{4} \mathrm{ClO}_{4} \\
\mathrm{KClO}_{4} \\
\mathrm{RbClO}_{4} \\
\mathrm{CsClO}_{4} \\
\mathrm{TIClO}_{4} \\
\mathrm{AgClO}_{4}\end{array}$ \\
\hline B-P-type & & & $\begin{array}{l}\mathbf{l}^{*} \\
\mathbf{2}\end{array}$ & $\begin{array}{l}1^{*} \\
2\end{array}$ & $\begin{array}{l}\mathbf{1}^{*} \\
2\end{array}$ & $\begin{array}{l}\mathbf{1}^{*} \\
\mathbf{2}\end{array}$ & $\begin{array}{l}\mathbf{1}^{*} \\
2\end{array}$ & $\begin{array}{l}1^{*} \\
2\end{array}$ & $\begin{array}{l}1,3^{*} \\
3 \\
1 \\
3 \\
1 \\
1 \\
1 \\
3,5^{*}\end{array}$ & $\begin{array}{l}1,3^{*} \\
3 \\
1 \\
3 \\
1 \\
1 \\
1 \\
3,5^{*}\end{array}$ & $\begin{array}{l}1,3^{*} \\
3 \\
1 \\
3 \\
1 \\
1 \\
1 \\
3,5^{*}\end{array}$ & $\begin{array}{l}\mathrm{NaClO}_{4} \\
\mathrm{NaClO}_{4} \\
\mathrm{NH}_{4} \mathrm{ClO}_{4} \\
\mathrm{KClO}_{4} \\
\mathrm{RbClO}_{4} \\
\mathrm{CsClO}_{4} \\
\mathrm{TlClO}_{4} \\
\mathrm{AgClO}_{4}\end{array}$ \\
\hline
\end{tabular}

accessible states (Tables 6 and 7). The two O-O distances close to $2.70 \AA$ listed for sodium $\left(314{ }^{\circ} \mathrm{C}\right)$ and potassium perchlorate, refer to B-type orientations of the anions. These distances may become accessible by small adjustments of the anion positions, which have a certain translational and positional freedom, as pointed out previously. This gives rise to the two $\mathbf{S}_{\mathrm{c}}{ }^{* *}$-values listed in Table 8. The actual configurational entropies originating in the present model lie probably somewhere between the limits given in Table 8 and are thus considerably uncertain in several cases. The importance of distinguishing between accessible and inacces- sible configurations among those implied statistically is clearly demonstrated for $\mathrm{AgClO}_{\iota}$, for which a configurational entropy far exceeding the experimental value is obtained on ignoring that many of the configurations indicated sta. tistically are actually blocked.

The rather large difference in computed configurational entropy of sodium perchlorate at the two experimental temperatures is attributable to the large difference in the values used for the $a$-axis (Table 1 ). The actual configurational entropy difference would be expected to be smaller than that indicated in Table 8, since the transition appears to be mostly completed

Acta Chem. Scand. A 28 (1974) No. 5 
Table 8. Observed transition entropies and calculated configurational entropies. For $\mathrm{NaClO}_{4}$ : $\Delta S_{\mathrm{t}}=\int_{T \mathrm{i}} T_{\mathrm{j}}\left(\Delta C_{\mathrm{p}} / T\right) \mathrm{d} T$, where $\Delta C_{\mathrm{p}}$ denotes the anomalous heat capacity observed in the transition and $T_{\mathrm{i}}-T_{\mathrm{f}}$ is the temperature interval of the transition. For the other compounds: $\Delta S_{\mathrm{t}}=$ $\Delta H_{\mathrm{t}} / T_{\mathrm{t}}$, where $\Delta H_{\mathrm{t}}$ and $T_{\mathrm{t}}$ are given in Table $1, \mathrm{~g}_{\mathrm{A}}=6, \mathrm{~g}_{\mathrm{B}}=8 . x_{\mathrm{A}}, x_{\mathrm{B}}=$ fraction of anions in A-and B-type positions, respectively (see text).

$S_{\mathrm{c}}{ }^{*}$-values are based on the assumption that configurations comprising $\mathrm{O}-\mathrm{O}$ separations only slightly less than $2.80 \AA$ are accessible.

$S_{\mathrm{c}}{ }^{* *}$-values are based on the assumption that configurations comprising $\mathrm{O}-\mathrm{O}$ separations close to $2.70 \AA$ involving at least one B-type orientation, are accessible. $S_{\mathrm{c}}$-values: both categories assumed inaccessible.

\begin{tabular}{|c|c|c|c|c|}
\hline Compound & $\begin{array}{l}\Delta S_{\mathrm{t}} \\
(\mathrm{cal} / \mathrm{mol} \mathrm{K})\end{array}$ & $x_{\mathrm{A}}$ & $\begin{array}{l}S_{\mathrm{c}} \\
(\mathrm{cal} / \mathrm{mol} \mathrm{K})\end{array}$ & $\begin{array}{l}S_{\mathrm{c}}^{*}, S_{\mathrm{c}}^{* *} \\
(\mathrm{cal} / \mathrm{mol} \mathrm{K})\end{array}$ \\
\hline $\begin{array}{l}\mathrm{NaClO}_{4} \\
\mathrm{NH}_{4} \mathrm{ClO}_{4} \\
\mathrm{KClO}_{4} \\
\mathrm{RbClO}_{4} \\
\mathrm{CsClO}_{4} \\
\mathrm{TlClO}_{4} \\
\mathrm{AgClO}_{4}\end{array}$ & $\begin{array}{r}4.24 \\
4.83 \\
5.65 \\
4.99 \\
3.63 \\
4.41 \\
\left\{\begin{array}{l}0.67 \\
1.85\end{array}\right. \\
\end{array}$ & 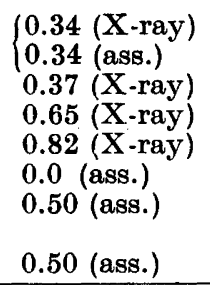 & $\begin{array}{l}1.80 \\
2.67 \\
4.36 \\
3.57 \\
3.22 \\
3.73 \\
4.20 \\
\\
1.02 \\
\end{array}$ & $\begin{array}{l}2.67^{* *}\left(314^{\circ} \mathrm{C}\right) \\
3.93^{*}\left(380^{\circ} \mathrm{C}\right) \\
4.86^{*} \\
3.83^{* *} \\
3.68^{*} \\
4.80^{*} \\
2.00^{*}\end{array}$ \\
\hline
\end{tabular}

at the lower temperature (Fig. 1). - Alternative orientations shown in Fig. 3, such as $\mathrm{C}$, may possibly contribute to the state of disorder in the given frame of metal ions, in addition to those already considered. However, even a low percentage of molecules in such positions would increase the configurational entropy by a considerable amount, particularly in case $\mathbf{C}$ because of the high statistical factor (Fig. 3), making quickly up for the difference between observed and calculated quantities in Table 8.

Another possibility is that instantaneous equilibriurn positions of neighbouring metal ions may be sufficiently displaced from the average positions, so that distinctly different equilibrium orientations become accessible. A certain contribution to the state of disorder may also come from positional disorder of the metal ions. ${ }^{\text {s1 }}$

Inspection of Table 8 indicates that there is little room for further disorder in the case of ammonium, cesium, silver and thallium perchlorate. For the others, the difference between observed and calculated entropy values is considerably larger. The discrepancy may largely originate in changes in the vibrational state associated with the phase transformation. ${ }^{18,41} \mathrm{~A}$ further investigation into this matter seems to be difficult and would evidently require more experimental information.
The computer programs used in the present work are written by the author.

Acknowledgements. The author is indebted to Dr. F. Grønvold and Mr. B. Lyng-Nielsen who measured the heat capacity of sodium perchlo. rate. Thanks are also due to Dr. B. F. Pedersen, Sentralinstituttet for industriell forskning (S. I.) and Dr. T. Ledaal by whose help the X-ray diffraction and diff. scan. cal. measurements became possible. Technical assistance by Mrs. T. L. Rolfsen (S. I.), Miss G. Teien and Miss A. Mjærum is gratefully acknowledged. Part of the work was financially supported by Norges almenvitenskapelige forskningsråd.

\section{REFERENCES}

1. Vorländer, D. and Kaascht, E. Ber. Deut. Chem. Ges. 56 B (1923) 1157.

2. Büsen, W. and Herrmann, K. Z. Kristallogr. 67. (1928) 405.

3. Gottfried, C. and Schusterius, C. Z. Kristallogr. 84 (1933) 65.

4. Venkatesan, K. Proc. Indian Acad. Sci. Sect. A 46 (1957) 134.

5. Mani, N. V. Ibid. 143.

6. Smith, H. G. and Levy, H. A. Acta Crystallogr. 15 (1962) 1201.

7. Zachariasen, W. H. Z. Kristallogr. 73 (1930) 141.

8. Gordon, S. and Campbell, C. Anal. Chem. 27 (1955) 1102.

9. Herrmann, K. and Ilge, W. Z. Kristallogr. 75 (1930) 41.

Acta Chem. Scand. A 28 (1974) No. 5 
10. Braekken, H. and Harang, L. Ibid. 538.

11. Kanellakopulos, B. J. Inorg. Nucl. Chem. 28 (1966) 813.

12. Markowitz, M. M. and Boryta, D. A. $J$. Amer. Rocket Soc. 32 (1962) 1941.

13. Markowitz, M. M. and Boryta, D. A. $J$. Phys. Chem. 69 (1965) 1114.

14. Krien, G. Explosivstoffe 5 (1967) 73.

15. Hoffmann, K. A. and Marian, P. H. Sitzber. Preuss. Akad. Wiss. Phys. Math. Kl. (1932) p. 448.

16. Finbak, Chr. and Hassel, O. Z. Phys. Chem. B 32 (1936) 130.

17. Zimm, B. H., Oriani, R. A. and Hoffman, J. D. Annu. Rev. Phys. Chem. 4 (1953) 207.

18. Darmon, I. and Brot, C. Mol. Cryst. 2 (1967) 301.

19. Janik, J. A., Janik, J. H. and Mayer, J. Phys. Status Solidi 44 (1971) 437.

20. Rensburg, D. J. J. and Schutte, C. J. H. J. Mol. Struct. 11 (1972) 229.

21. Westrum, Jr., E. F. and Justice, B. H. $J$. Chem. Phys. 50 (1969) 5083.

22. Riehl, J. W., Wang, R. and Bernard, H. W., J. Chem. Phys. 58 (1973) 508.

23. Grønvold, F. Acta Chem. Scand. 21 (1967) 1695.

24. Solbakk, J. K. and Strømme, K. O. Acta Chem. Scand. 23 (1969) 300.

25. Kahn, R., Fourme, R., André, D. and Renaud, M. Acta Crystallogr. B 29 (1973) 131.

26. Strømme, K. O. Unpublished results.

27. Johansen, H. Chem. Phys. Lett. 11 (1971) 466.

28. Slater, J. C., J. Chem. Phys. 41 (1964) 3199.

29. Strømme, K. O. Acta Chem. Scand. 23 (1969) 1616.

30. Strømme, K. O. Ibid. 1625.

31. Strømme, K. O. Acta Chem. Scand. 25 (1971) 211.

32. Strømme, K. O. Acta Chem. Scand. 24 (1970) 1475 and 1477.

33. Andersen, S. and Wadsley, A. D. Acta Crystallogr. 15 (1962) 194.

34. Wilhelmi, K.-A. Ark. Kemi 26 (1967) 141.

35. Strutural Reports $9(1942-44) 228$ and 11 (1947-48) 366 .

36. Lindley, P. F. and Woodward, P. J. Chem. Soc. $A$ (1966) 123.

37. Hanson, H. P., Herman, F., Lea, J. D. and Skillman, S. Acta Crystallogr. 17 (1964) 1040.

38. de Boer, J. L. and Vos, A. Acta Crystallogr. $B 28$ (1972) 839.

39. Anzenhofer, K. and Hewitt, T. G. $Z$. Kristallogr. 134 (1971) 54.

40. James, R. W. The Optical Principles of the Diffraction of $X$-Rays S. Bell and Sons, London 1958.

41. Brot, C. J. Phys. (Paris) Colloq. C5a 32 (1971) 223.

Received January 21, 1974.

Acta Chem. Scand. A 28 (1974) No. 5 